\title{
Shock Sensitivity of LX-04 at Elevated Temperatures
}

\author{
P.A. Urtiew \\ C.M. Tarver \\ J.W. Forbes \\ F. Garcia
}

This paper was prepared for submittal to the 1997 APS Topical Conference on Shock Compression of Condensed Matter Amherst, MA

July 27 - August 1, 1997

July 1997

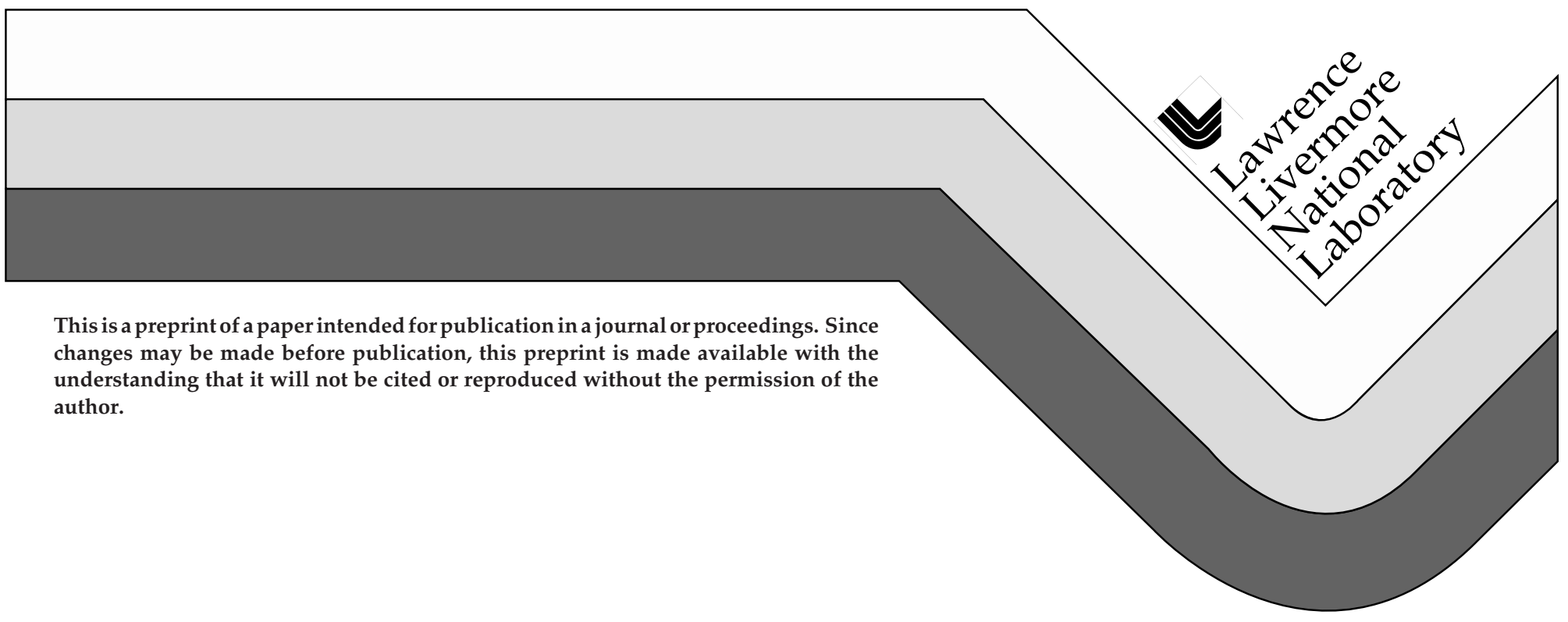




\section{DISCLAIMER}

This document was prepared as an account of work sponsored by an agency of the United States Government. Neither the United States Government nor the University of California nor any of their employees, makes any warranty, express or implied, or assumes any legal liability or responsibility for the accuracy, completeness, or usefulness of any information, apparatus, product, or process

disclosed, or represents that its use would not infringe privately owned rights. Reference herein to any specific commercial product, process, or service by trade name, trademark, manufacturer, or otherwise, does not necessarily constitute or imply its endorsement, recommendation, or favoring by the United States Government or the University of California. The views and opinions of authors expressed herein do not necessarily state or reflect those of the United States Government or the University of California, and shall not be used for advertising or product endorsement purposes. 


\title{
SHOCK SENSITIVITY OF LX-04 AT ELEVATED TEMPERATURES
}

\author{
P. A. Urtiew, C. M. Tarver, J. W. Forbes and F. Garcia \\ Lawrence Livermore National Laboratory, \\ P.O. Box 808, L-282, Livermore, CA 94551
}

\begin{abstract}
Hazard scenarios can involve multiple stimuli, such as heating followed by fragment impact (shock). The shock response of LX-04 (85 weight \% HMX and 15 weight \% Viton binder) preheated to temperatures near $170 \mathrm{C}$ is studied in a $10.2 \mathrm{~cm}$ bore diameter gas gun using embedded manganin pressure gauges. The pressure histories at various depths in the LX-04 targets and the run distances to detonation at several input shock pressures are measured and compared to those obtained in ambient temperature LX-04. The hot LX-04 is significantly more shock sensitive than ambient LX-04. Ignition and Growth reactive flow models are developed for ambient and hot LX-04 to allow predictions of impact scenarios that can not be tested directly.
\end{abstract}

\section{INTRODUCTION}

With safety issues playing a dominate role in present-day energetic materials technology, concern is increasing about the relative safety of solid high explosives exposed to extreme environmental conditions. High energy materials based on octahydro-1,3,5,7-tetranitro-1,3,5,7-tetrazocine

(HMX) are particularly important. LX-04, which contains 85 weight \% HMX and 15 weight \% Viton binder, is a widely used HMX-based plastic bonded explosive. The sensitivity of LX-04 to single stimulus such as heat, impact, and shock has been studied. Hazard scenarios can involve multiple stimuli, such as heating to temperatures close to thermal explosion conditions followed by fragment impact, producing a shock in the hot explosive. This scenario has previously been studied for triaminotrinitrobenzene (TATB)-based insensitive solid explosives under various thermal and confinement conditions (1-3). The shock sensitivity of heated LX-04 is compared to that of ambient temperature LX-04 using embedded manganin pressure gauges (4) and reactive flow calculations (5).

\section{EXPERIMENTAL}

The experimental geometry for the heated LX-04 embedded gauge experiments is shown in Fig. 1. A $12.7 \mathrm{~mm}$ thick, $90 \mathrm{~mm}$ diameter aluminum flyer plate impacted a target consisting of a $6 \mathrm{~mm}$ thick, $90 \mathrm{~mm}$ diameter aluminum buffer plate, a $20 \mathrm{~mm}$ thick, $90 \mathrm{~mm}$ diameter LX-04 charge and a $6 \mathrm{~mm}$ thick, $90 \mathrm{~mm}$ diameter aluminum back plate. Heaters were placed within the aluminum plates and heated the LX-04 to approximately $170 \mathrm{C}$ at a rate of $10 \mathrm{C} /$ minute. When the nine thermocouples in the aluminum and LX-04 showed that the whole assembly was within a few degrees of $170 \mathrm{C}$, the shot

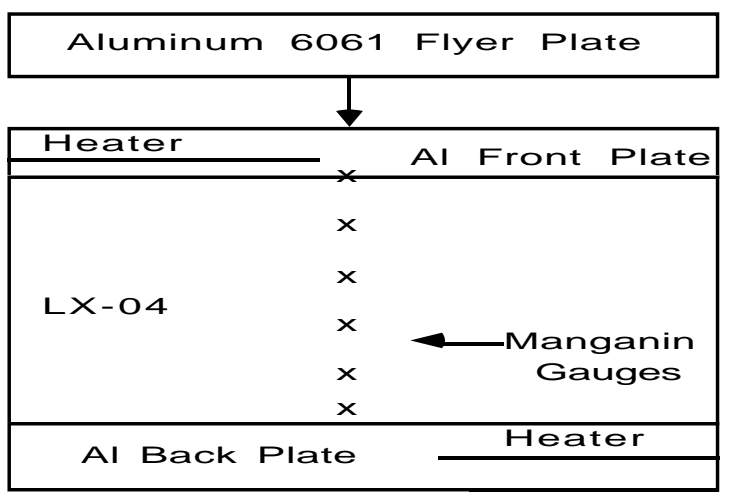

FIGURE 1. Geometry of the heated LX-04 embedded manganin pressure gauge experiments 
was fired. Four shots with aluminum flyer velocities of $0.373,0.515,0.643$, and $0.886 \mathrm{~mm} / \mu \mathrm{s}$ produced shock pressures of $1.5,2.2,2.8$, and $4.3 \mathrm{GPa}$, respectively. Six manganin pressure gauges placed along the LX-04 charge axis measured the pressure histories at $0,5,10,13,16$ and $18 \mathrm{~mm}$ into LX-04 in the three lower pressure shots and at $0,2,4,7$, 10 , and $15 \mathrm{~mm}$ into LX-04 in the highest pressure shot. One experiment was fired using ambient temperature LX-04 and Teflon flyer, buffer, and back plates with a velocity of $0.956 \mathrm{~mm} / \mu \mathrm{s}$ to impart a shock pressure of $3.0 \mathrm{GPa}$ for comparison.

\section{REACTIVE FLOW MODELING}

The Ignition and Growth reactive flow model uses two Jones-Wilkins-Lee (JWL) equations of state, one for the unreacted explosive and another one for the reaction products, in the temperature dependent form:

$$
\mathrm{p}=\mathrm{A} \mathrm{e}^{-\mathrm{R}_{1} \mathrm{~V}}+\mathrm{B} \mathrm{e}^{-\mathrm{R}_{2} \mathrm{~V}}+\omega \mathrm{C}_{\mathrm{V}} \mathrm{T} / \mathrm{V}
$$

where $\mathrm{p}$ is pressure in Megabars, $\mathrm{V}$ is relative volume, $\mathrm{T}$ is temperature, $\omega$ is the Gruneisen coefficient, $\mathrm{C}_{\mathrm{V}}$ is the average heat capacity, and $\mathrm{A}, \mathrm{B}$, $\mathrm{R}_{1}$ and $\mathrm{R}_{2}$ are constants. The equations of state are fitted to the available shock Hugoniot data. The reaction rate law is:

$$
\begin{aligned}
& d F / d t=I(1-F)^{b}\left(\rho / \rho_{o}-1-a\right)^{x}+G_{1}(1-F)^{c} F^{d} p^{y} \\
& 0<\mathrm{F}<\mathrm{F}_{\text {igmax }} \quad 0<\mathrm{F}<\mathrm{F}_{\text {G1max }} \\
& +\mathrm{G}_{2}(1-\mathrm{F})^{\mathrm{e}} \mathrm{Fg}^{\mathrm{g}} \mathrm{p}^{\mathrm{Z}} \\
& F_{G 2 \min }<\mathrm{F}<1
\end{aligned}
$$

where $\mathrm{F}$ is the fraction reacted, $\mathrm{t}$ is time in $\mu \mathrm{s}, \rho$ is the current density in $\mathrm{g} / \mathrm{cm}^{3}, \rho_{\mathrm{o}}$ is the initial density, $\mathrm{p}$ is pressure in Mbars, and $\mathrm{I}_{1} \mathrm{G}_{1}, \mathrm{G}_{2}, \mathrm{a}, \mathrm{b}, \mathrm{c}, \mathrm{d}$, e, $\mathrm{g}, \mathrm{x}, \mathrm{y}$, and $\mathrm{z}$ are constants. This three term reaction rate law models the three stages of reaction generally observed during shock initiation of pressed solid explosives (5). The equation of state parameters for ambient and hot LX-04, aluminum, and Teflon, and the Ignition and Growth rate law parameters are listed in Table 1. The reaction rates are similar to those used for LX-10 (6) and PAX2A (7). The hot spot growth rate parameter $G_{1}$ in Eq. (2) is varied to match the experimental data.

\section{COMPARISON OF RESULTS}

Table 2 contains the experimental flyer velocities, impact pressures, and run distances to detonation for the ambient temperature LX-04 shot and the four hot LX-04 shots. Figure 2 shows the measured and calculated pressure histories at the six gauge locations in ambient temperature LX-04 impacted by a Teflon flyer plate at $0.956 \mathrm{~mm} / \mu \mathrm{s}$. The gauge records show rapid pressure increases, but detonation is not quite attained in the $20 \mathrm{~mm}$ thick charge. The agreement between the experimental records and the Ignition and Growth calculations is excellent. A growth reaction rate coefficient $\mathrm{G}_{1}$ value of 100 is used for LX-04 in Fig. 2. This value is similar to the values of $\mathrm{G}_{1}=120$ for LX-10 (94.5\% HMX, 5.5 $\%$ Viton) and $\mathrm{G}_{1}=90$ for PAX2A, which contains $85 \%$ HMX in a different binder.

Two comparisons for hot (170C) LX-04 are shown in Figs. 3 and 4 . Roth (8), in a shock initiation study of PBX 9404 at 150C, found that its density at that temperature had decreased from 1.84 to 1.77 $\mathrm{g} / \mathrm{cm}^{3}$. The density of LX-04 is assumed to decrease from 1.866 to $1.77 \mathrm{~g} / \mathrm{cm}^{3}$ at $170 \mathrm{C}(443 \mathrm{~K})$. The unreacted equation of state for hot LX-04 in Table 1 is adjusted for these initial conditions. Figure 3 contains the records for the $0.643 \mathrm{~mm} / \mu \mathrm{s}$ aluminum flyer impact velocity experiment. The gauge records and calculations show that transition to detonation occurs very close to the $10 \mathrm{~mm}$ deep gauge position. Figure 4 shows the results for the $0.515 \mathrm{~mm} / \mu \mathrm{s}$

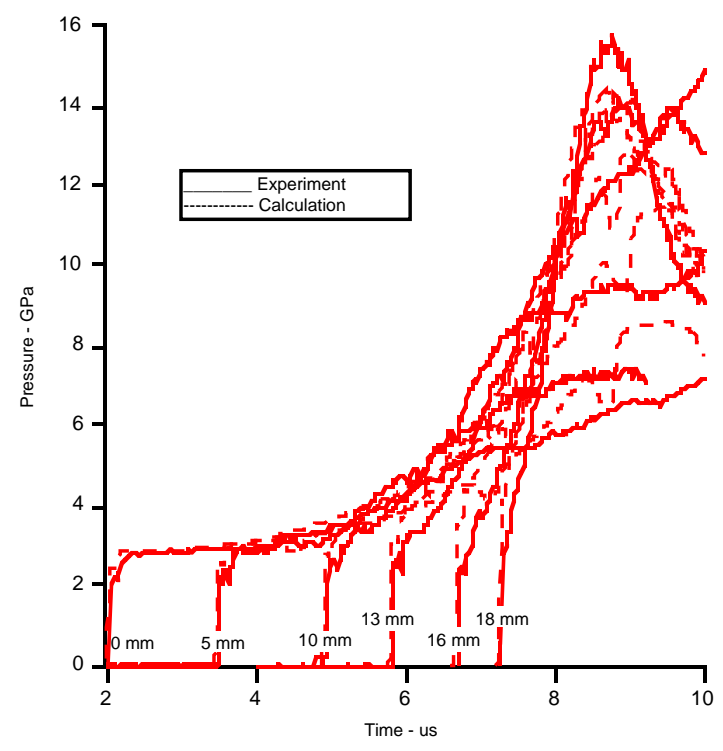

FIGURE 2. Pressure histories for ambient temperature LX-04 
shock initiated by a Teflon flyer plate at $0.956 \mathrm{~mm} / \mu \mathrm{s}$

TABLE 1. Equation of State and Reaction Rate Parameters

1. Ignition and Growth Model Parameters for LX-04

Unreacted JWL Product JWL

Reaction Rate Parameters

A. Ambient temperature $\left(T_{0}=298 K ; \rho_{\mathrm{O}}=1.866 \mathrm{~g} / \mathrm{cm}^{3}\right.$; Shear Modulus=0.05 Mbar; Yield Strength=0.002 Mbar)

$\begin{array}{llll}\mathrm{A}=9522 \mathrm{Mbar} & \mathrm{A}=8.364 \mathrm{Mbar} & \mathrm{I}=7.43 \mathrm{e}+11 & \mathrm{G}_{2}=400 \\ \mathrm{~B}=-0.05922 \mathrm{Mbar} & \mathrm{B}=0.1298 \mathrm{Mbar} & \mathrm{a}=0.0 & \mathrm{e}=0.333 \\ \mathrm{R}_{1}=14.1 & \mathrm{R}_{1}=4.62 & \mathrm{~b}=0.667 & \mathrm{~g}=1.0 \\ \mathrm{R}_{2}=1.41 & \mathrm{R}_{2}=1.25 & \mathrm{x}=20.0 & \mathrm{z}=2.0 \\ \omega=0.8867 & \omega=0.42 & \mathrm{G}_{1}=100 & \mathrm{~F}_{\text {igmax }}=0.3 \\ \mathrm{C}_{\mathrm{V}}=2.7806 \mathrm{e}-5 \mathrm{Mbar} / \mathrm{K} & \mathrm{C}_{\mathrm{V}}=1.0 \mathrm{e}-5 \mathrm{Mbar} / \mathrm{K} & \mathrm{y}=2.0 & \mathrm{~F}_{\mathrm{G} 1 \max =0.5} \\ & \mathrm{E}_{\mathrm{O}}=0.095 \mathrm{Mbar} & \mathrm{c}=0.667, \mathrm{~d}=0.333 & \mathrm{~F}_{\mathrm{G} 2 \min }=0.5\end{array}$

B. Hot LX-04 $\left(\mathrm{T}_{\mathrm{o}}=443 \mathrm{~K} ; \rho_{\mathrm{o}}=1.77 \mathrm{~g} / \mathrm{cm}^{3} ;\right.$ Shear Modulus=0.0474 Mbar $)$

$\mathrm{B}=-0.0740834 \mathrm{Mbar} \quad \mathrm{G}_{1}=210$

2. Gruneisen Parameters for Inert Materials

$$
\mathrm{p}=\rho_{\mathrm{o}} \mathrm{c}^{2} \mu\left[1+\left(1-\gamma_{\mathrm{o}} / 2\right) \mu-\mathrm{a} / 2 \mu^{2}\right] /\left[1-\left(\mathrm{S}_{1}-1\right) \mu-\mathrm{S}_{2} \mu^{2} /(\mu+1)-\mathrm{S}_{3} \mu^{3} /(\mu+1)^{2}\right]^{2}+\left(\gamma_{\mathrm{o}}+\mathrm{a} \mu\right) \mathrm{E}
$$
where $\mu=\left(\rho / \rho_{0}\right)-1$ and $E$ is thermal energy

\begin{tabular}{llllllll} 
Inert & $\rho_{\mathrm{O}}\left(\mathrm{g} / \mathrm{cm}^{3}\right)$ & $\mathrm{c}(\mathrm{mm} / \mu \mathrm{s})$ & $\mathrm{S}_{1}$ & $\mathrm{~S}_{2}$ & $\mathrm{~S}_{3}$ & $\gamma_{\mathrm{o}}$ & $\mathrm{a}$ \\
6061-T6 Al & 2.703 & 5.24 & 1.4 & 0.0 & 0.0 & 1.97 & 0.48 \\
Teflon & 2.15 & 1.68 & 1.123 & 3.98 & -5.8 & 0.59 & 0.0 \\
\hline \hline
\end{tabular}

TABLE 2. Experimental flyer velocities, impact pressures, and run distances to detonation

\begin{tabular}{llcll}
\hline \hline $\begin{array}{l}\text { Flyer Velocity } \\
(\mathrm{mm} / \mu \mathrm{s})\end{array}$ & $\begin{array}{l}\text { Impact Pressure } \\
(\mathrm{GPa})\end{array}$ & $\begin{array}{c}\text { LX-04 Temperature } \\
(\mathrm{C})\end{array}$ & \multicolumn{2}{c}{ Experimental Run to Detonation Results } \\
0.965 (Teflon) & 3.0 & 25 & 20 & Time $(\mu \mathrm{s})$ \\
$0.373(\mathrm{Al})$ & 1.5 & $165-169$ & $>20$ & 7.8 \\
$0.515(\mathrm{Al})$ & 2.2 & $167-171$ & 14 & $>10$ \\
$0.643(\mathrm{Al})$ & 2.8 & $166-170$ & 9 & 5.4 \\
$0.886(\mathrm{Al})$ & 4.5 & $166-170$ & 4 & 3.6 \\
\hline \hline
\end{tabular}

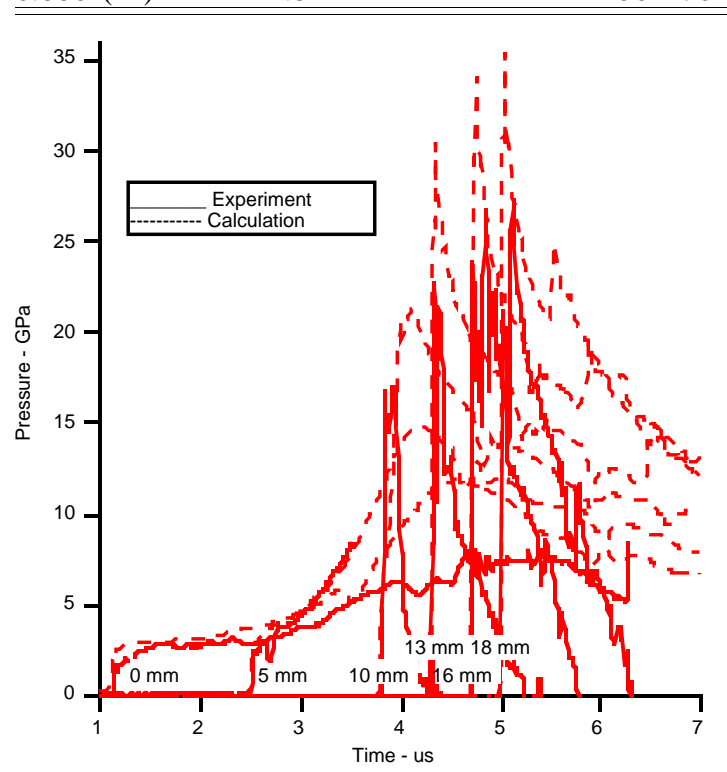

FIGURE 3. Pressure histories for hot (170C) LX-04 shock initiated by an aluminum flyer at $0.643 \mathrm{~mm} / \mu \mathrm{s}$ 


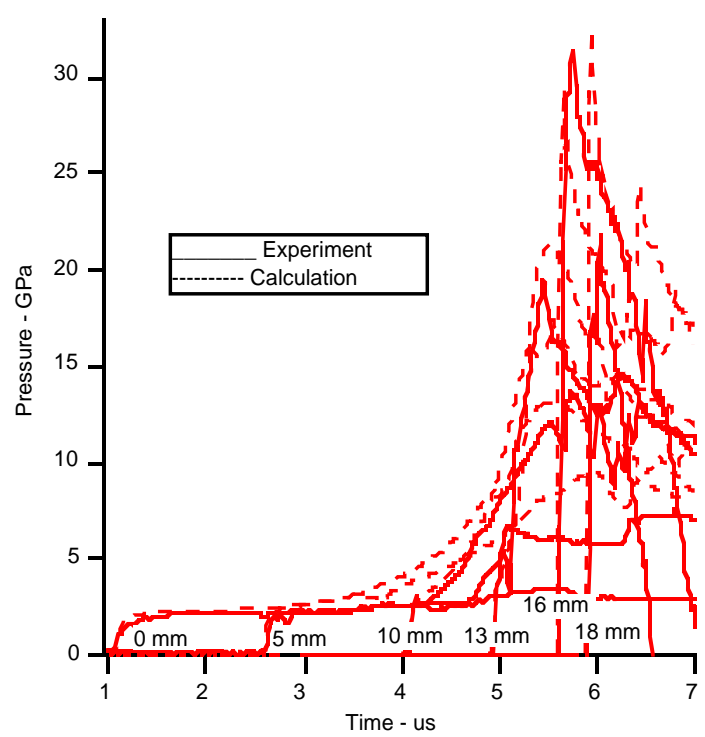

FIGURE 4. Pressure histories for hot LX-04 shock initiated by an aluminum flyer at $0.515 \mathrm{~mm} / \mu \mathrm{s}$

aluminum flyer experiment and the corresponding reactive calculations. The detonation transition takes place between the $13 \mathrm{~mm}$ gauge and the $16 \mathrm{~mm}$ gauge positions. The two sets of gauge records in Figs. 3 and 4 clearly demonstrate that LX-04 is significantly more shock sensitive at $170 \mathrm{C}$ than at ambient temperature. The highest aluminum impact velocity, $0.886 \mathrm{~mm} / \mu \mathrm{s}$, produces a $4.3 \mathrm{GPa}$ shock in hot LX-04 and a $4 \mathrm{~mm}$ run distance to detonation.

For these three impact pressures, the Ignition and Growth model yields excellent results using a value of $G_{1}=210$, which is essentially double the ambient hot spot growth rate. The increases in shock front pressure measured by the embedded gauges in Figs. 3 and 4 for hot LX-04 are similar to those in Fig. 2 for ambient LX-04. This indicates that the amount of LX-04 ignited near the shock front does not increase substantially at $170 \mathrm{C}$ and that the increase in shock sensitivity is mainly due to the more rapid growth of reacting hot spots into the surrounding preheated explosive (9). The modeling results support this conclusion, since the only increase with temperature is in the $\mathrm{G}_{1}$ coefficient. The lowest aluminum impact velocity, $0.373 \mathrm{~mm} / \mu \mathrm{s}$, in Table 2 imparts about $1.5 \mathrm{GPa}$ into the hot LX-04. Little or no reaction is observed at this input shock pressure, and thus the run distance to detonation at $1.5 \mathrm{GPa}$ is much greater than $20 \mathrm{~mm}$.

The increased shock sensitivity of LX-04 at 170C is shown in terms of run distance to detonation versus input shock pressure in Fig. 5. Also shown in Fig. 5 are the "Pop Plots" for ambient LX-04 and PBX 9404 (10). Raising the temperature of LX-04 increases its shock sensitivity close to that of PBX 9404, which contains 94\% HMX and an energetic binder based on nitrocellulose.

\section{SUMMARY}

The shock sensitivity of LX-04 heated to $170 \mathrm{C}$ has been quantitatively demonstrated to be greater than that of ambient temperature LX-04. Its run distance to detonation versus impact pressure curve is similar to that of PBX 9404. The Ignition and Growth reaction rates for LX-04 are similar to those previously developed for other HMX-based formulations. The only changes for hot LX-04 are a lower initial density and an increase in the hot spot growth coefficient $G_{1}$ from 100 to 210 . This implies that the increased sensitivity of LX-04 at $170 \mathrm{C}$ is mainly due to the faster growth of hot spot

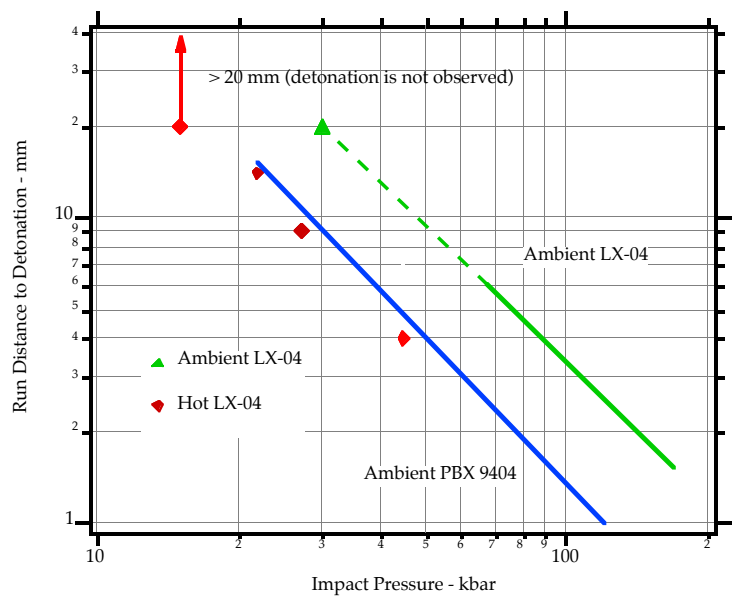

FIGURE 5. Run distance to detonation versus input shock pressure for ambient and heated LX-04 and PBX 9404

reactions following ignition. Additional experiments are planned in which the LX-04 is completely confined to limit thermal expansion during heating.

\section{ACKNOWLEDGMENTS}

This work was performed under the auspices of the U.S. Department of Energy by Lawrence Livermore National Laboratory (contract no. W-7405-ENG-48). 


\section{REFERENCES}

1. Urtiew, P. A., Tarver, C. M., Maienschein, J. L., and Tao, W. C., Combustion and Flame 105, 43-53 (1996).

2. Urtiew, P. A., Cook, T. M., Maienschein, J. L., and Tarver, C. M., Tenth International Detonation Symposium, ONR 33395-12, Boston, MA, 1993, pp. 139-147.

3. Dallman, J. C. and Wackerle, J., Tenth International Detonation Symposium, ONR 33395-12, Boston, MA, 1993, pp. $130-138$.

4. Urtiew, P. A., Erickson, L. M., Hayes, B., and Parker, N. L., Combustion, Explosion and Shock Waves 22, 597-614 (1986).

5. Tarver, C. M., Hallquist, J. O., and Erickson, L. M., Eighth Symposium (International) on Detonation, NSWC MP 86-194, Albuquerque, NM, 1985, pp. 951-961.

6. Tarver, C. M., Urtiew, P. A., Chidester, S. K., and Green, L. G., Propellants, Explosives, Pyrotechnics 18, 117-127 (1993).

7. Baker, E. L., Schimel, B., and Grantham, W. J., in Shock Compression of Condensed Matter-1995, Schmidt, S. C. and Tao, W. C., eds., AIP Press, New York, 1995, pp. 409-412.

8. Roth, J., Fifth Symposium (International) on Detonation, ACR184, Pasadena, CA, 1970, pp. 219-230.

9. Tarver, C. M., Chidester, S. K., and Nichols, A. L., J. Phys. Chem. 100, 5794-5799 (1996).

10. Dobratz, B. M. and Crawford, P. C., LLNL Explosives Handbook, Lawrence Livermore National Laboratory Report UCRL-52997 Change 2, 1985. 


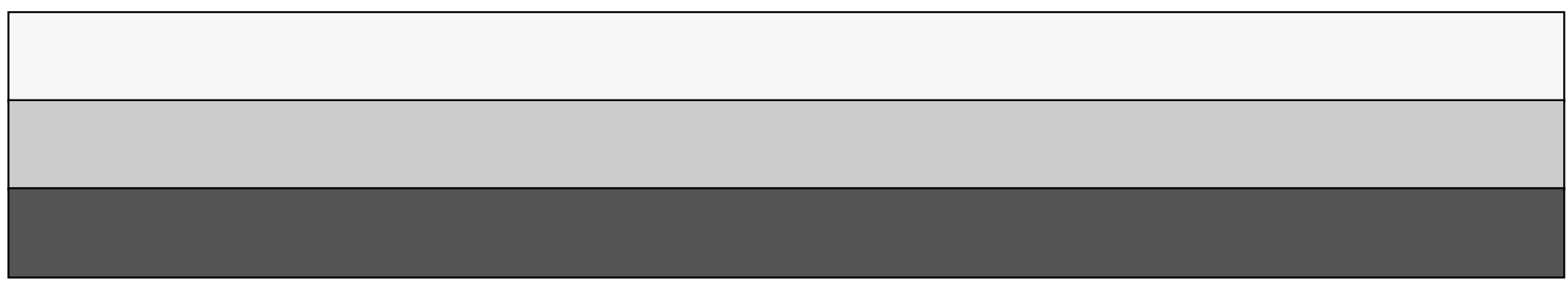

